\title{
Author Correction: Anti-trypanosomatid drug discovery: an ongoing challenge and a continuing need
}

Mark C. Field, David Horn, Alan H. Fairlamb, Michael A. J. Ferguson, David W. Gray, Kevin D. Read, Manu De Rycker, Leah S. Torrie, Paul G. Wyatt, Susan Wyllie and Ian H. Gilbert

Nature Reviews Microbiology (2017) https://doi.org/10.1038/nrmicro.2016.193

Published online 27 February 2017; corrected 5 June 2017

The structures of nifurtimox in Table 1 were incorrect and have been updated in the pdf and online. The authors apologize for any confusion caused.

https://doi.org/10.1038/s41579-018-0085-1 I Published online 11 September 2018 